\title{
Glucagon-Like Peptide-1-Responsive Catecholamine Neurons in the Area Postrema Link Peripheral Glucagon- Like Peptide-1 with Central Autonomic Control Sites
}

\author{
Hiroshi Yamamoto, ${ }^{1}$ Toshiro Kishi, ${ }^{2}$ Charlotte E. Lee, ${ }^{1}$ Brian J. Choi, ${ }^{1}$ Hui Fang, ${ }^{1}$ Anthony N. Hollenberg, ${ }^{1}$ \\ Daniel J. Drucker, ${ }^{3}$ and Joel K. Elmquist ${ }^{1,2}$ \\ ${ }^{1}$ Department of Medicine and Division of Endocrinology and ${ }^{2}$ Department of Neurology and Program in Neuroscience, Beth Israel Deaconess Medical \\ Center, Harvard Medical School, Boston, Massachusetts 02215, and ${ }^{3}$ Department of Medicine, Toronto General Hospital and the Banting and Best Diabetes \\ Centre, University of Toronto, Toronto, Ontario, Canada M5G 2C4
}

Glucagon-like peptide-1 (GLP-1) released from the gut is an incretin that stimulates insulin secretion. GLP-1 is also a brain neuropeptide that has diverse central actions, including inhibition of food and water intake, gastric emptying, and stimulation of neuroendocrine responses characteristic of visceral illness. Both intravenous and intracerebroventricular administration of GLP-1 receptor (GLP-1R) agonists increase blood pressure and heart rate and induce Fos-like immunoreactivity (Fos-IR) in autonomic regulatory sites in the rat brain. The area postrema (AP) is a circumventricular organ and has been implicated in processing visceral sensory information. GLP-1Rs are densely expressed in the AP, and peripheral GLP-1R agonists induce Fos-IR in AP neurons to a greater degree than intracerebroventricular administration. Because the AP lacks a blood-brain barrier, we hypothesized that the AP is a key site for peripheral GLP-1 to activate central autonomic regulatory sites. In this study, we found that many tyrosine hydroxylase (TH)-containing neurons in the AP expressed GLP-1Rs and Fos-IR after intravenous GLP-1R agonists. Furthermore, intravenous but not intracerebroventricular GLP-1R agonists induced $T H$ transcription in the AP in vivo. In addition, GLP-1R agonists directly activated $T H$ transcription in an in vitro cell system. Finally, we found that GLP-1-responsive TH neurons in the AP innervate autonomic control sites, including the parabrachial nucleus, nucleus of solitary tract, and ventrolateral medulla. These findings suggest that catecholamine neurons in the AP link peripheral GLP-1 and central autonomic control sites that mediate the diverse neuroendocrine and autonomic actions of peripheral GLP-1.

Key words: GLP-1; area postrema; tyrosine hydroxylase; blood-brain barrier; insulin; c-Fos; catecholamine neurons; autonomic regulatory system

\section{Introduction}

Glucagon-like peptide-1 (GLP-1) is a peptide hormone that is released by enteroendocrine $\mathrm{L}$ cells in the intestine (Creutzfeldt, 2001). GLP-1 is also a neuropeptide (Jin et al., 1988) regulating several neuroendocrine and autonomic responses (Turton et al., 1996). Both intravenous and intracerebroventricular administrations of GLP-1 receptor (GLP-1R) agonists increase blood pressure and heart rate and induce Fos-like immunoreactivity (FosIR) in autonomic regulatory groups (Barragan et al., 1999; Seeley et al., 2000; Yamamoto et al., 2002). We found previously that intravenous administration of the GLP-1R agonist exendin-4 $(\mathrm{EXN}-4)$ induced Fos-IR in neurons of the area postrema (AP) to a greater extent than intracerebroventricular EXN-4. The AP lacks a blood-brain barrier and contributes to the regulation of several autonomic functions, including blood pressure and heart rate (Ferguson and Marcus, 1988; Chan and Sawchenko, 1994),

\footnotetext{
Received July 16, 2002; revised Jan. 16, 2003; accepted Jan. 17, 2003

This work was supported by National Institutes of Health Grants DK59751 and DK56116 and Juvenile Diabetes Research Foundation Grant 2000-559. We thank Dr. Gordon Yaney for the INS-1 cells, Dr. D. M. Chikaraishi for $T H$ gene, and Quan Ha for expert technical assistance. We also thank Clifford B. Saper for helpful comments on this manuscript.

Correspondence should be addressed to Dr. Joel K. Elmquist, Division of Endocrinology, Beth Israel Deaconess Medical Center, 347 Research North, 99 Brookline Avenue, Boston, MA 02215. E-mail: jelmquis@caregroup.harvard.edu. Copyright $\odot 2003$ Society for Neuroscience $\quad 0270-6474 / 03 / 232939-08 \$ 15.00 / 0$
}

food and water intake (Edwards and Ritter, 1981), emesis (Carpenter, 1990), conditioned taste aversion (Gallo et al., 1988), and the secretion of neuroendocrine hormones (Iovino et al., 1988). In the AP, GLP-1 binding sites (Goke et al., 1995; Orskov et al., 1996) and GLP-1 receptor mRNA (Merchenthaler et al., 1999) are abundant, suggesting that the AP is a key site for peripheral GLP-1 to activate central autonomic pathways.

Neurons in the AP express tyrosine hydroxylase (TH) (Armstrong et al., 1982), and catecholamine neurons in the AP have been thought to be involved in mediating several autonomic functions (Armstrong et al., 1982; Miceli et al., 1987). The downstream targets of AP neurons are relatively restricted and include the external lateral parabrachial nucleus (PBel), the rostral ventrolateral medulla (RVLM), and the commissural, medial, and dorsomedial divisions of nucleus of solitary tract (NTS) (van der Kooy and Koda, 1983; Shapiro and Miselis, 1985; Miceli et al., 1987; Herbert et al., 1990; Cunningham et al., 1994). Notably, these sites are thought to regulate autonomic responses attributable to projections to hypothalamic neuroendocrine neurons and vagal motor and sympathetic preganglionic neurons.

Circulating GLP-1 may directly activate AP neurons; however, the downstream targets of GLP-1-responsive neurons in the AP remain unclear. In the current study, we characterized GLP1 -responsive neurons in the AP using combined in situ hybrid- 
ization histochemistry (ISHH) and immunohistochemistry. We also investigated $T H$ transcriptional activity in the AP after intravenous and intracerebroventricular EXN-4 administration with a TH intron-specific RNA (heteronuclear; hnRNA) probe. We also assessed $T H$ transcriptional activity in vitro using GLP-1Rexpressing cells to determine whether EXN-4 directly activates TH gene transcription. Finally, we injected a retrograde tracer Fluorogold (FG) into the PBel, RVLM, and caudal NTS to determine whether TH-containing AP neurons are activated by intravenous EXN-4 and also target key autonomic control sites.

\section{Materials and Methods}

Animals and surgical procedures. Adult male pathogen-free Sprague Dawley rats (250-350 gm; Taconic Farms, Germantown, NY) were housed in a light-controlled (12 hr light/dark cycle; lights on at 7:00 A.M.) and temperature-controlled $\left(21.5-22.5^{\circ} \mathrm{C}\right)$ environment. The animals and procedures used were approved by the Harvard Medical School and Beth Israel Deaconess Medical Center Institutional Animal Care and Use Committees. The rats were monitored daily after surgery to assess general appearance, body weight, and behavior.

Rats were anesthetized with isoflurane (induction, 5\%; maintenance, $2 \%)$ and were implanted with a SILASTIC catheter in the femoral vein (intravenous administration). For intravenous administration of the peptides, a SILASTIC catheter containing heparinized saline $[10 \mathrm{U} / \mathrm{ml}$ pyrogen-free saline (PFS); Sigma, St. Louis, MO] was inserted and sutured in place, as described previously (Elmquist and Saper, 1996; Yamamoto et al., 2002). The end of the catheter was passed under the skin of back, exteriorized between the scapulae, and plugged with a sterile wire stylet.

Thirty-six rats were used for retrograde tracing. In each rat, a single injection was made using iontophoresis and a glass pipette filled with a $2.5 \%$ solution of FG (Fluorochrome, Englewood, NJ) dissolved in saline. The driving current (5-6 $\mu \mathrm{A}, 200 \mathrm{msec}, 2 \mathrm{~Hz}$ ) was delivered for a period of 5-10 min. The injections were guided by stereotaxic coordinates from Paxinos and Watson (1986). Coordinates for the PBel were as follows (in $\mathrm{mm}$ ): anterior, 9.0; lateral, 2.4; and ventral, 7.0 from bregma. Coordinates for the RVLM were as follows (in $\mathrm{mm}$ ): anterior, 12.3; lateral, 2.2; and ventral, 10.0 from bregma. Coordinates for the caudal NTS were as follows (in mm): lateral, 1.0; and ventral, 1.0, at the level of the obex.

Animal perfusion and histology. After survival times of 3 to $5 \mathrm{~d}$, rats were injected with $1 \mu \mathrm{g} / \mathrm{kg} \mathrm{EXN-4}(n=23)$ (American Peptide Company, Sunnyvale, CA) or PFS ( $n=13)$. For single-label Fos experiments, rats were injected with $1 \mu \mathrm{g} / \mathrm{kg}$ GLP-1 $\left(7-36^{\text {amide }}\right)(n=4)$ (Peninsula Laboratories, San Carlos, CA), $1 \mu \mathrm{g} / \mathrm{kg}$ albumin-conjugated GLP-1 $(n=$ 4) (ConjuChem, Montreal, Quebec, Canada), or PFS $(n=4)$. All drugs were administered between 9:00 and 12 A.M. Two hours after administration of peptides or PFS, rats were deeply anesthetized with isoflurane and perfused transcardially with diethyl pyrocarbonate (DEPC)-treated $0.9 \%$ saline, followed by $10 \%$ neutral Formalin (Sigma). For TH hnRNA in situ hybridization studies, rats were perfused $0 \mathrm{~min}, 15 \mathrm{~min}, 30 \mathrm{~min}, 1$ hr, $2 \mathrm{hr}, 6 \mathrm{hr}$, or $24 \mathrm{hr}$ after administration of EXN-4 or PFS ( $n=3$ for each group). Tissues were removed and postfixed in the same fixative for $4 \mathrm{hr}$, submerged in $20 \%$ sucrose, and cut at $30 \mu \mathrm{m}$ (1:5 series) on a freezing microtome.

Immunohistochemistry. The procedures for immunohistochemistry were performed as reported previously (Elmquist and Saper, 1996; Zhang et al., 2000; Yamamoto et al., 2002). For single-label immunohistochemistry, sections were pretreated with $0.3 \%$ hydrogen peroxide in PBS for $30 \mathrm{~min}$ at room temperature and then in 3\% normal donkey serum (Jackson ImmunoResearch, West Grove, PA) with $0.25 \%$ Triton $\mathrm{X}-100$ in PBS (PDT) for $1 \mathrm{hr}$, followed by overnight incubation in Fos rabbit primary antisera $[A b 5 ; 1: 100,000$ in PDT; Oncogene, San Diego, CA] or FG rabbit primary antisera (1:20,000 in PDT; Chemicon, Temecula, CA) at room temperature. After washing in PBS, sections were incubated in biotinylated donkey anti-rabbit IgG (1:1000; Jackson ImmunoResearch) for $1 \mathrm{hr}$ at room temperature and then incubated with avidin-biotin complex (ABC; Vectastain Elite ABC kit; 1:500 in PBS; Vector Laboratories, Burlingame, CA) for $1 \mathrm{hr}$. A combination of $0.04 \%$ diaminobenzidine tetrahydrochloride (DAB) (Sigma), 0.01\% nickel ammonium sulfate (Fisher Scientific, Pittsburgh, PA), 0.01\% cobalt chloride (Fisher Scientific), and $0.01 \%$ hydrogen peroxide dissolved in PBS was used for the chromogen reaction for 5-10 min with two successive rinses in PBS. For FG staining, the nickel and cobalt were omitted from the solution. The tissue sections were mounted onto subbed slides, air dried, dehydrated in alcohol, cleared in xylenes, and then coverslipped with Permaslip (Alban Scientific, St. Louis, MO).

For double-label immunohistochemistry, the sections processed for Fos were blocked in PDT for $2 \mathrm{hr}$ and then incubated in FG rabbit primary antisera (1:20,000 in PDT; Chemicon) or mouse anti-TH (1: 20,000 in PDT; Chemicon) overnight. The sections were processed as described above using DAB as a chromogen.

For triple-label immunohistochemistry, the tissue sections were incubated in Fos antisera and were processed as described above, but we used $3 \%$ normal goat serum and incubated sections in the DAB solution without nickel sulfate and cobalt chloride, resulting in a brown nuclear reaction product. Sections were then incubated in FG rabbit primary antisera and mouse anti-TH overnight at room temperature. After washing in PBS, sections were incubated in Alexa 488-conjugated goat anti-rabbit IgG (1:200 in PDT; Molecular Probes, Eugene, OR) and Alexa 594conjugated goat anti-mouse IgG (1:200 in PDT; Molecular Probes) for 2 hr. The Fos-IR was observed with bright-field optics, and the TH-IR and the retrograde label was observed using the appropriate filter system.

In situ hybridization histochemistry. The protocol for ISHH was a modification of that reported previously (Chan et al., 1993; Elias et al., 1998; Yamamoto et al., 2002). Antisense GLP-1R and TH intron ${ }^{35}$ S-labeled riboprobes were generated from cDNA templates as described previously (Wheeler et al., 1993; Scrocchi et al., 1996; Yamamoto et al., 2002). For generation of antisense, plasmids were linearized by digestion with HindIII (GLP-1R) and SpeI (TH intron) and subjected to in vitro transcription with T7 (GLP-1R and TH intron) polymerase according to the protocol of the manufacturer (Ambion, Austin, TX).

Dual-label in situ hybridization histochemistry-immunohistochemistry. The protocol used for combined ISHH and immunohistochemistry was a modification of that described previously (Priestley et al., 1993; Elias et al., 1998). Tissue sections were first processed for ISHH for GLP-1R using free-floating sections, followed by immunohistochemistry for $\mathrm{TH}$, Fos, and FG. Before hybridization, sections were rinsed in DEPC-treated PBS, $\mathrm{pH} 7.0$, and were pretreated with $1 \%$ sodium borohydrate (Sigma) in DEPC-PBS for 15 min at room temperature. After washing in DEPCPBS, sections were rinsed in $0.1 \mathrm{M}$ tetraethylammonium (TEA), $\mathrm{pH}$ 8.0, and incubated in $0.25 \%$ acetic anhydrate in $0.1 \mathrm{~m}$ TEA for $10 \mathrm{~min}$. Subsequently, sections were rinsed in $2 \times$ SSC and incubated in hybridization mixture (containing the GLP-1R or TH intron probes) for $12-16 \mathrm{hr}$ at $57^{\circ} \mathrm{C}$. The cRNA probes were diluted to $10^{6} \mathrm{cpm} / \mathrm{ml}$ in hybridization solution of $50 \%$ formamide, $10 \mathrm{~mm}$ Tris- $\mathrm{HCl}$ (Invitrogen, Carlsbad, CA), $\mathrm{pH}$ 8.0, $5.0 \mathrm{mg}$ of tRNA (Roche, Indianapolis, IN), $10 \mathrm{~mm}$ dithiothreitol, $10 \%$ dextran sulfate, $0.3 \mathrm{M} \mathrm{NaCl}, 1 \mathrm{~mm}$ EDTA, $\mathrm{pH} 8$, and $1 \times$ Denhardt's solution (Sigma). The following morning, sections were rinsed in $4 \times$ SSC and incubated in $0.002 \%$ RNAase A (Roche) with $0.5 \mathrm{M} \mathrm{NaCl}, 10 \mathrm{~mm}$ Tris- $\mathrm{HCl}, \mathrm{pH} 8$, and $1 \mathrm{~mm}$ EDTA for $30 \mathrm{~min}$ at $37^{\circ} \mathrm{C}$. Sections were rinsed with $2 \times$ SSC and washed in $50 \%$ formamide in $0.2 \times$ SSC at $50^{\circ} \mathrm{C}$. Subsequently, sections were rinsed in decreasing concentrations of SSC at $50^{\circ} \mathrm{C}$ for $1 \mathrm{hr}, 0.2 \times \mathrm{SSC}$ at $55^{\circ} \mathrm{C}$ for $1 \mathrm{hr}$, and $0.2 \times$ SSC at $60^{\circ} \mathrm{C}$ for $1 \mathrm{hr}$. Sections were next washed in PBS thoroughly and then were processed for immunohistochemistry as described above. After staining for Fos, $\mathrm{TH}$, and FG, sections were mounted onto SuperFrost Plus slides (Fisher Scientific), and air dried. Slides were then dehydrated in graded ethanol (70, 80, 90, 95, and 100\%) containing $0.3 \mathrm{M} \mathrm{NH}_{4} \mathrm{OAc}$ and delipidated in chloroform for $10 \mathrm{~min}$, followed by 100 and $95 \%$ ethanol. Slides were placed in X-ray film cassettes with BMR-2 film (Eastman Kodak, Rochester, NY) for 2-3 d and dipped in NTB2 photographic emulsion (Eastman Kodak), dried, and stored with desiccant in foil-wrapped slide boxes at $4^{\circ} \mathrm{C}$ for 2-3 weeks. Slides were developed with D-19 developer (Eastman Kodak) and dehydrated ethanols, cleared in xylene, and coverslipped with Permaslip.

In all procedures, the estimates of cell counts (Fos, TH, and FG) were done by an observer blinded to the treatment groups. The data were not 
corrected for double counting and a stereological technique was not used, because the objectives we were counting (nuclei and retrogradely labeled cells) did not change in size and section thickness did not vary between groups. Hence, because all double-label studies are inherently qualitative, our results are meant to provide relative data but are not meant to be accurate estimates of absolute cell counts. Data were analyzed by ANOVA and differences between groups by Fisher's PLSD test.

Luciferase assay. INS-1 cells (obtained from Dr. Gordon Yaney, Boston University School of Medicine, Boston, MA) were cultured in RPMI 1640 containing $10 \mathrm{~mm}$ HEPES, 10\% fetal bovine serum, $1 \mathrm{~mm}$ pyruvic acid, $100 \mathrm{U} / \mathrm{ml}$ penicillin, $100 \mu \mathrm{g} / \mathrm{ml}$ streptomycin, and $50 \mu \mathrm{M}$ 2-mercaptoethanol (Asfari et al., 1992). Cells were maintained at $37^{\circ} \mathrm{C}$ in a humidified incubator gassed with $5 \% \mathrm{CO}_{2}$. Cell cultures were passaged by tripsinization and subcultured once per week.

A $4.5 \mathrm{~kb}$ fragment of the $5^{\prime}$ flanking region of rat tyrosine hydroxylase (Schimmel et al., 1999) (provided by Dr. D. M. Chikaraishi, Duke University Medical Center, Durham, NC) was fused to the coding sequence of the luciferase gene in the plasmid pA3LUC to generate rTHLUC (Harris et al., 2001). Adherent INS-1 cells grown to $50-70 \%$ confluence in Falcon $35 \mathrm{~mm}$ tissue culture dishes (Becton Dickinson, Rutherford, NJ) were trypsinized and transferred to Falcon $35 \mathrm{~mm}$ tissue culture dishes at $1 \mathrm{ml} /$ well cell suspension and incubated overnight (14-18 hr). Cells were transfected using Lipofectamine 2000 (Invitrogen, Grand Island, NY). Cells were rinsed in serum-free culture medium before the addition of $200 \mu \mathrm{l}$ of transfection Lipofectamine mixture containing $2.0 \mu \mathrm{g}$ of plasmid DNA (rTHLUC or RSVLUC), including 20 ng of cytomegalovirus$\beta$-galactosidase expression vector to control for transfection efficiency.

EXN-4 was dissolved in RPMI culture medium, added to Falcon 35 $\mathrm{mm}$ tissue culture dishes, and added $12 \mathrm{hr}$ after transfection, and the cells were lysed and assayed for luciferase and $\beta$-galactosidase activity after 16 hr of exposure. GLP-1R antagonist, [des-His ${ }_{1}$, Glu ${ }_{9}$ ] exendin-4 (Seeley et al., 2000), was added 30 min before addition of exendin-4. All experiments were performed in duplicate. Statistical analysis was performed using ANOVA combined with Fisher's PLSD test.

Production of photomicrographs. Photomicrographs were captured with a digital camera (AxioCam; Zeiss, Thornwood, NY) mounted directly on the microscope (Axioskop 2; Zeiss) and a Dell Pentium 4 computer. Image editing software [Axiovision (Zeiss) and Adobe Photoshop (Adobe Systems, Mountain View, CA)] was used to combine photomicrographs into plates. Only the sharpness, contrast, and brightness were adjusted. All figures were printed on a dye-sublimation printer (Kodak 8670; Eastman Kodak). For drawings (see Fig. 4), cytoarchitectonic details were generated using a camera lucida.

\section{Results}

\section{GLP-1R mRNA is expressed by TH neurons in the AP}

Using ISHH coupled with immunohistochemistry, we found that a high percentage of TH-immunoreactive neurons in the AP coexpressed GLP-1R mRNA. The GLP-1R mRNA was detected with a ${ }^{35} \mathrm{~S}$-labeled riboprobe using the free-floating method, followed by TH immunohistochemistry. Double-labeled cells were observed as silver grains overlying brown cytoplasmic staining (Fig. $1 A, B$ ). The level of coexpression was high, because $>90 \%$ of TH-immunoreactive neurons also expressed GLP-1R mRNA in the AP. Single-labeled TH-immunoreactive neurons or GLP-1Rexpressing neurons were found but were clearly in the minority.

\section{GLP-1R agonists activate GLP-1R-expressing TH neurons in the AP}

We demonstrated recently that EXN-4 dose dependently increases blood pressure and heart rate and induces Fos-IR in the rat brain $2 \mathrm{hr}$ after intravenous administration of EXN-4 (Yamamoto et al., 2002). In the current study, we found that TH-immunoreactive neurons also contained EXN-4-induced Fos-IR in the AP (Fig. 1C,D). Using ISHH coupled with immunohistochemistry, GLP-1R mRNA expressing neurons in the AP were found to contain Fos-IR after intravenous EXN-4 (Fig. 1 E).
Additionally, we detected many triple-labeled cells (Fos plus GLP-1R mRNA plus TH), demonstrating that GLP-1Rexpressing $\mathrm{TH}$-immunoreactive neurons are activated by EXN-4 (Fig. 1E, F, Table 1).

Because EXN-4 is a protease-resistant long-acting GLP-1R agonist that is derived from lizard, we also examined Fos-IR after intravenous administration of native mammalian GLP-1 (7$\left.36^{\text {amide }}\right)$. Relatively few Fos-immunoreactive cells were detected in the AP after administration of intravenous GLP-1. To determine whether a stable protease-resistant GLP-1 albumin conjugate that does not cross the blood-brain barrier would also activate GLP-1-responsive neurons in the AP, we assessed Fos activation after administration of CJC-1131, a GLP-1 molecule that forms a rapid covalent peptide-albumin conjugate after administration of the native peptide in vivo. This stabilized GLP-1 albumin complex has slightly reduced potency compared with native GLP-1 but has a longer half-life in the blood stream (Kim et al., 2003). The distribution pattern of Fos-immunoreactive neurons induced by intravenous albumin-conjugated GLP-1 was similar to that induced by same dose of intravenous EXN-4. These regions included the PVH, PBel, RVLM, AP, and NTS (Fig. $2 A-D$ ). Similar to our previous results, dual-label immunohistochemistry revealed that many $\mathrm{TH}$-immunoreactive neurons in these nuclear groups also contained albumin-conjugated GLP-1induced Fos-IR (Fig. $1 K, L$ ).

\section{GLP-1R agonist activates TH gene transcription in vivo and in vitro}

To determine whether GLP-1 agonists directly activated TH in specific neurons, we constructed and used an intron-specific (hnRNA) probe developed in our laboratory as a tool to study in vivo transcriptional activity of the $\mathrm{TH}$ gene (Yamamoto et al., 2002). In the current study, we observed that a few AP neurons showed a detectable nuclear hybridization signal at baseline. Intravenous administration of PFS did not further induce TH hnRNA expression at any time points examined (Fig. 3A). In contrast, intravenous administration of EXN-4 provoked a robust and rapid increase in TH hnRNA expression in the AP (Fig. 3B). Specifically, TH hnRNA expression was induced $15 \mathrm{~min}$ after intravenous injection and returned to baseline by $24 \mathrm{hr}$.

To determine whether EXN-4 can directly activate the TH gene in neuroendocrine cells, INS-1 islet cells were transiently transfected with $4.5 \mathrm{~kb}$ of the $5^{\prime}$ flanking sequence of the TH gene fused to the luciferase reporter gene (rTHLUC). INS-1 cells endogenously express the GLP-1R (Kieffer et al., 1996; Skoglund et al., 2000). Luciferase activity in the transfected INS-1 cells was stimulated in a concentration-dependent manner by EXN-4 $\left(\mathrm{EC}_{50}\right.$ of $\left.1.6 \times 10^{-11} \mathrm{M}\right)$ (Fig. $\left.3 \mathrm{C}\right)$. At the maximally effective concentration, EXN-4 induced a $477 \%$ increase in luciferase activity over basal activity. The specificity of the responses for the GLP-1R was confirmed by the demonstration that pretreatment with a GLP-1R antagonist, [des-His ${ }_{1}$, Glu 9 ] exendin-4 (Seeley et al., 2000), dose dependently inhibited the action of EXN-4 (Fig. 3D).

\section{Distribution of GLP-1R agonist-activated catecholamine neurons projecting to the PBel, RVLM, and caudal NTS}

To identify targets of GLP-1R-expressing neurons in the AP, we injected the retrograde tracer FG into the PBel, RVLM, and caudal NTS (Fig. $4 A-C$ ). These sites have been shown previously to be innervated by AP neurons (Shapiro and Miselis, 1985; Cunningham et al., 1994). We found FG-labeled AP neurons after 

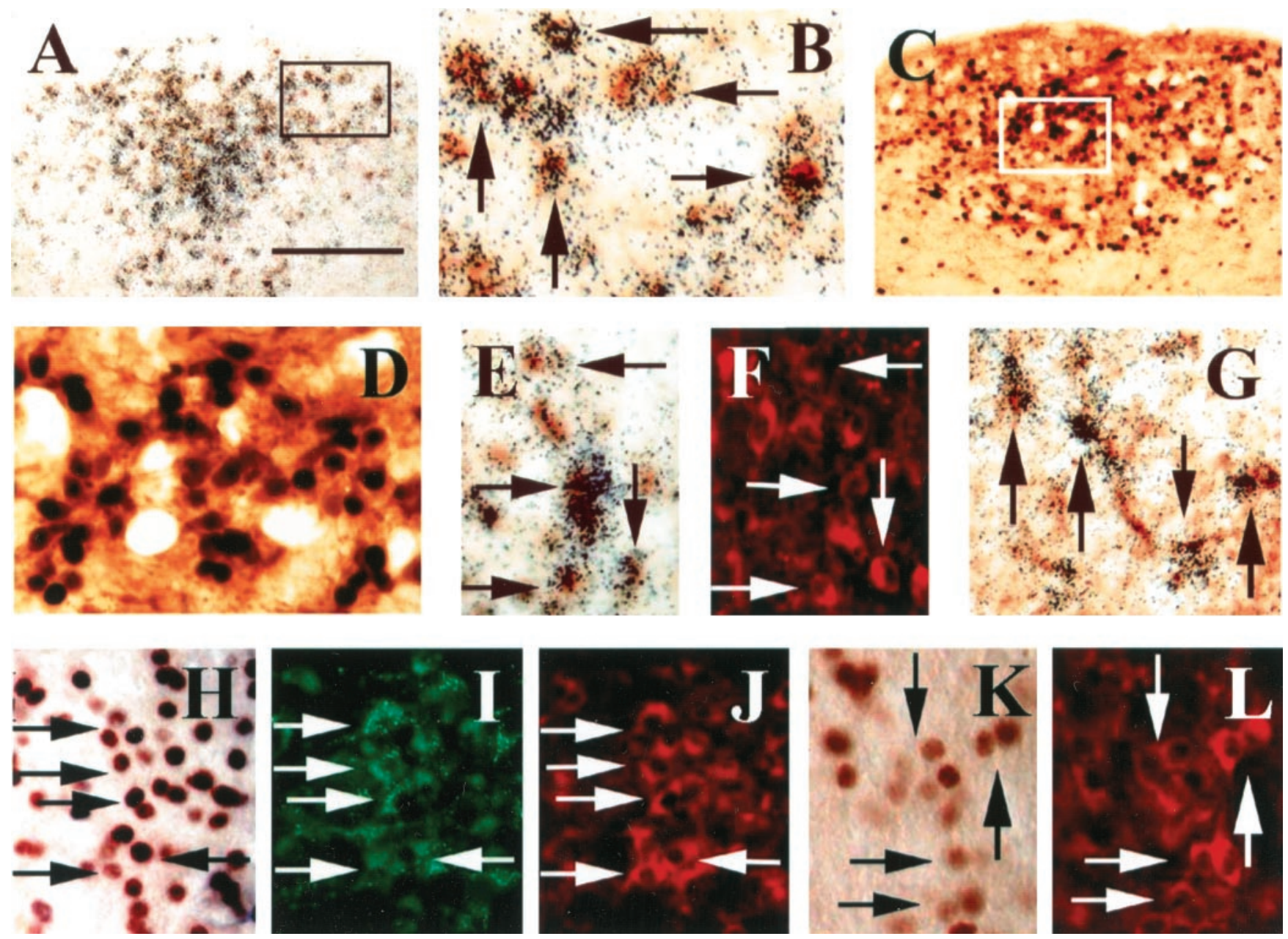

Figure 1. Intravenous EXN-4 activated neurons in the AP. A,B,In situ hybridization coupled with immunohistochemistry demonstrates TH-immunoreactive neurons expressing GLP-1R in the AP. The neurons containing clusters of silver grains were hybridized with a GLP- $1 \mathrm{R}^{35} \mathrm{~S}$-labeled riboprobe. The TH-immunoreactive neurons contain brown cytoplasmic reaction product. $B$ is a higher magnification of $A$ (arrows indicate double-labeled neurons). C, D, Dual-label immunohistochemistry demonstrates that TH-immunoreactive neurons (brown cytoplasm) contain Fos-IR (black nuclei) 2 hr after intravenous EXN-4 in the AP. D is a higher magnification of $C . E, F$, In situ hybridization coupled with dual-label immunohistochemistry demonstrates that many GLP-1R-expressing TH-immunoreactive neurons (red neurons in $F$ ) are activated by intravenous EXN-4. The neurons containing clusters of silver grains were hybridized with a GLP-1R ${ }^{35} S$-labeled riboprobe, and the Fos-immunoreactive neurons contain brown cytoplasmic reaction product in $E$ (arrows indicate triple-labeled neurons). $G$, In situ hybridization coupled with immunohistochemistry demonstrates that many retrogradely labeled neurons (brown cytoplasm) after FG injection into the PBel also express GLP-1R mRNA (clusters of silver grains) (arrows indicate double-labeled neurons). H-J, Triple-label immunohistochemistry reveals that many retrogradely labeled neurons (green neurons in $/$ ) in the AP contain TH-IR (red cytoplasm in $J$ ) and also contain Fos-IR (brown nuclei in $H$ ) after intravenous EXN-4 (arrows indicate triple-labeled neurons). $K$, $L$, Dual immunohistochemistry demonstrates that TH-immunoreactive neurons (red cytoplasm in $L$ ) also contain intravenous albumin-conjugated GLP-1-induced Fos-IR (brown nuclei in K) (arrows indicate double-labeled neurons). Scale bar: A, C, $200 \mu \mathrm{m} ; B, D, E-L, 50 \mu \mathrm{m}$.

injections of FG into the PBel, RVLM, and caudal NTS (Fig. $4 D-F)$. The distribution of cells containing FG-like immunoreactivity (FG-IR; retrogradely labeled neurons) in the AP after these injections was similar to those reported previously (Shapiro and Miselis, 1985; Kachidian and Pickel, 1993; Cunningham et al., 1994). Characteristically, very high numbers of retrogradely labeled AP neurons were observed after injections of FG into PBel (Fig. 4G, Table 1). Lower numbers of retrogradely labeled AP neurons were observed by injecting into the RVLM and caudal NTS (Fig. 4H,I, Table 1).

Five rats had FG injections centered in the PBel, RVLM, and caudal NTS and also received intravenous EXN-4. In each injection site, the numbers of the retrogradely labeled AP neurons in EXN-4-treated rats were not distinct from those in PFS-treated rats (Table 1). On the other hand, we observed the typical distribution pattern of Fos-IR after intravenous EXN-4 and many double-labeled neurons (containing Fos-IR and FG-IR) in the AP (Figs. $1 H, I, 3 G$ ). In contrast, saline injections resulted in no
Table 1. Estimates of GLP-1-responsive neurons innervating autonomic control sites

\begin{tabular}{lccc}
\hline & RVLM & Caudal NTS & \multicolumn{1}{c}{ PBel } \\
\hline FG-IR (PFS) & $45.6 \pm 18.2$ & $85.0 \pm 17.9$ & $232 \pm 70.2$ \\
FG-IR (EXN-4) & $76.6 \pm 14.0$ & $97.0 \pm 11.2$ & $218.3 \pm 93.1$ \\
$\begin{array}{l}\text { Double-labeled, FG-IR-Fos-IR (PFS) } \\
\text { Double-labeled, FG-IR-Fos-IR } \\
\quad \text { (EXN-4) }\end{array}$ & $0 \pm 0$ & $0 \pm 0$ & $0 \pm 0$ \\
$\begin{array}{c}\text { Percentage of doubles, FG-IR-Fos-IR/ } \\
\quad \text { total FG-IR }\end{array}$ & $11.2 \pm 1.2^{* *}$ & $5.7 \pm 0.7^{* *}$ & $33.0 \pm 14.6$ \\
$\begin{array}{l}\text { Triple-labeled, FG-IR-Fos-IR-TH-IR } \\
\quad \text { (PFS) }\end{array}$ & $15.3 \pm 3.2^{* *}$ & $6.2 \pm 1.6^{*}$ & $14.0 \pm 2.3^{* *}$ \\
$\begin{array}{l}\text { Triple-labeled, FG-IR-Fos-IR-TH-IR } \\
\quad(\text { EXN-4) }\end{array}$ & $0 \pm 0$ & $0 \pm 0$ & $0 \pm 0$ \\
$\begin{array}{l}\text { Percentage of triples, FG-IR-Fos-IR- } \\
\text { TH-IR/total FG-IR }\end{array}$ & $8.7 \pm 1.3^{* *}$ & $4.3 \pm 0.9^{* *}$ & $18.0 \pm 7.5$ \\
\hline
\end{tabular}

Values represent estimates of mean \pm SEM counts of cells. Data were analyzed by ANOVA and differences between groups by Fisher's PLSD test. ${ }^{*} p<0.05$ and ${ }^{* *} p<0.01$ compared with PFS-treated rats; $n=3$ for each treatment. 


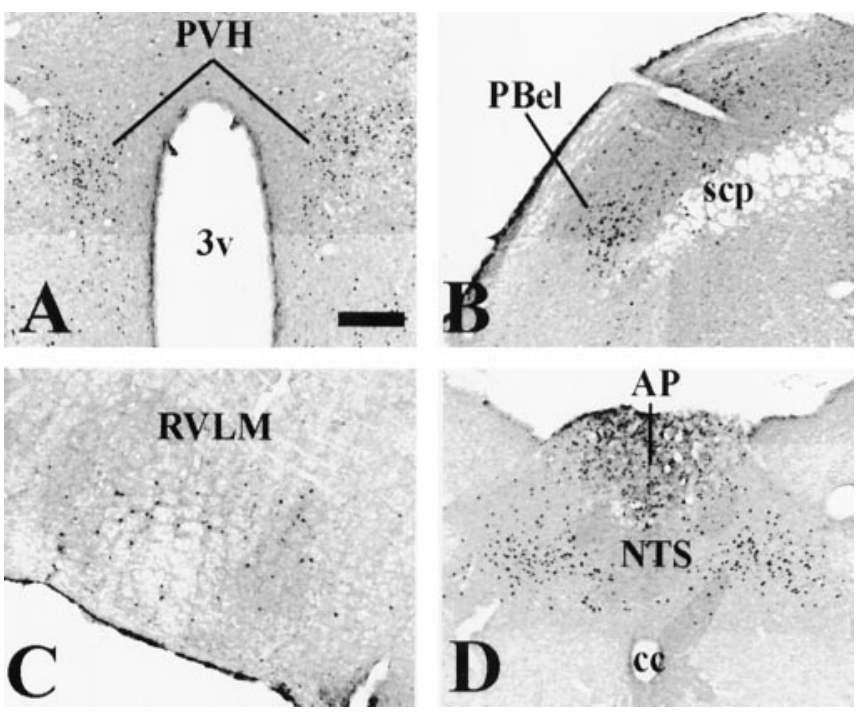

Figure 2. Distribution of intravenous albumin-conjugated GLP-1-induced Fos-IR in the rat brain. $A-D$, A series of photomicrographs demonstrate Fos-IR in neurons $2 \mathrm{hr}$ after intravenous albumin-conjugated GLP-1 in several brain regions. These neurons include the PVH $(A)$, the $\operatorname{PBel}(B)$, the RVLM $(C)$, and the PA and the NTS $(D) .3 v$, Third ventricle; scp, superior cerebellar peduncle; $c c$, central canal. Scale bar: $A-D, 200 \mu \mathrm{m}$.

Fos-IR neurons in the AP. Thus, both the number and percentage of double-labeled (Fos plus FG) neurons was significantly higher in EXN-4-treated rats than those in PFS-treated rats (Table 1). Using fluorescent immunohistochemistry, we found that the number of triple-labeled (Fos plus FG plus TH) neurons was significantly higher in EXN-4-treated rats (Figs. $1 \mathrm{H}-J$, 3G-I; Table 1).
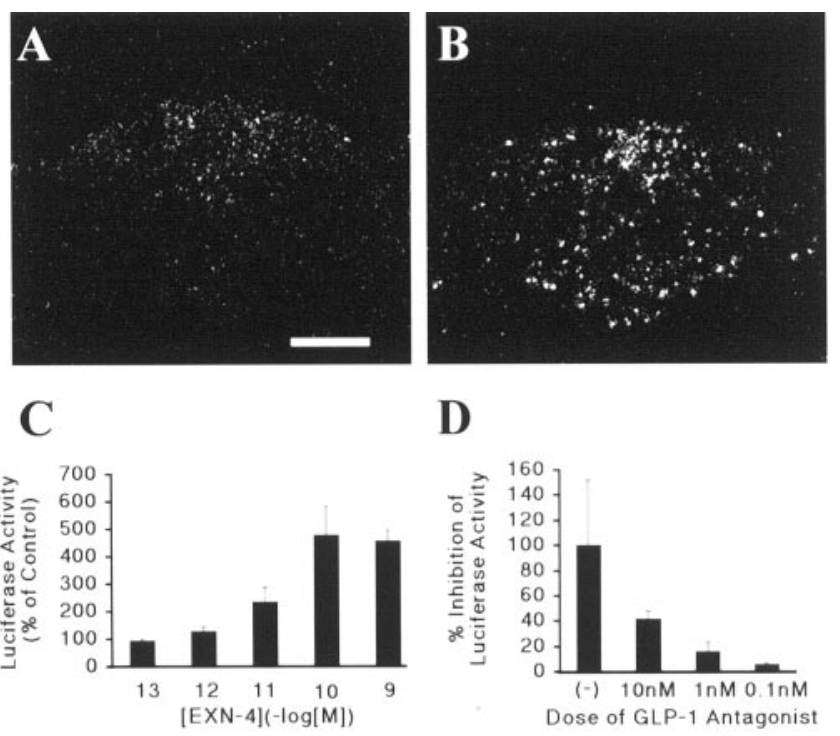

D

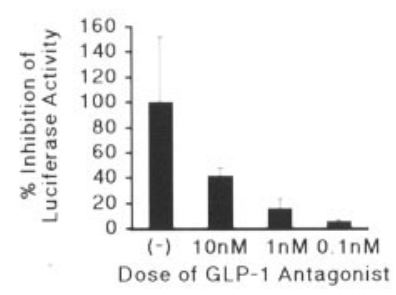

Figure 3. EXN-4 activates TH transcription in vivo and in vitro. $A, B$, In situ hybridization immunohistochemistry demonstrates that TH transcription is activated by $15 \mathrm{~min}$ after administration of intravenous EXN-4 $(B)$ but not by intravenous PFS $(A)$ in the AP. C, INS-1 cells were transfected with a TH promoter-luciferase vector and treated with increasing concentrations of EXN-4. Shown is the dose-response relationship for stimulation of TH promoter-driven reporter activity by EXN-4. The data are displayed as percentage of basal in which basal activity (without ligand) is set at 100\%.D, An identical paradigm to Figure 3 (was used except, as indicated, cells were pretreated with increasing concentrations of the GLP-1 antagonist. The results are quantified as percentage inhibition of luciferase activity in which $100 \%$ represents the activity of transfected cells treated with $10^{-10} \mathrm{M}$ EXN-4 alone.

\section{Discussion}

Using ISHH combined with immunohistochemistry, we found that many catecholamine neurons in the AP expressed GLP-1R and also displayed Fos-IR after intravenous EXN-4. Furthermore, intravenous EXN-4 increased TH transcription in neurons of the AP in vivo, and EXN-4 directly activated the TH promoter using in vitro transfection assays. Together, these studies suggest that engagement of GLP-1R in the AP by EXN-4 leads to TH transcription via promoter elements in the TH gene. In addition, we found that many GLP-1-responsive catecholamine neurons in the AP projected to the PBel, RVLM, and caudal NTS. These findings suggest that catecholamine neurons in the AP are responsive to peripheral GLP-1 and target autonomic regulatory sites. Efferent projections of the AP to the commissural, medial, and dorsomedial parts of NTS have been reported previously (Kachidian and Pickel, 1993; Cunningham et al., 1994). We centered our injections on the NTS at the level of the AP, including the commissural, medial, and dorsomedial parts. Some of the injections were relatively large. However, because the NTS lies below the AP, we deliberately made injections that avoided tracer intrusion into the AP.

GLP-1 released from gut has a short half-life as it is rapidly degraded by the ubiquitous enzyme dipeptidyl peptidase- 4 (DPP-IV). In contrast, modified peptidase-resistant GLP-1 analogs and lizard EXN-4 are highly resistant to degradation by DPP-IV, exhibit longer half-lives, and are substantially more potent than native GLP-1 both in vitro and in vivo (Goke et al., 1993; Young et al., 1999). In this study, we used EXN-4 as a GLP-1R agonist to assess Fos-IR after a single intravenous injection and to determine potential downstream mediators of GLP-1R activation.

A previous study did not report Fos expression in the AP after intravenous native GLP-1 (Rowland et al., 1997). We hypothesize that this difference is likely attributable to the increased half-life of EXN-4 compared with native GLP-1. For example, the distribution of Fos-IR after administration of EXN-4 is very similar to the pattern detected after albumin-conjugated GLP-1. Additionally, we found that EXN-4 induced relatively little Fos expression in other circumventricular organs, including the subfornical organ and organum vasculosum of the lamina terminalis. These sites typically express Fos-IR after inflammatory stimuli (Elmquist et al., 1997). Nonetheless, we cannot rule out the possibility that some of the induction of Fos-IR may be attributable to the antigenicity of the non-native GLP-1 agonist.

\section{Functional roles of GLP-1-responsive neurons in the AP}

Neurons in the AP have been hypothesized to be involved in rapid homeostatic responses to changes in fluid and nutrient balances, including the regulation of blood pressure (Chan and Sawchenko, 1994) and heart rate (Ferguson and Smith, 1991), food and water intake (Edwards and Ritter, 1981; Ritter and Taylor, 1990), emesis (Carpenter, 1990), conditioned taste aversion (Gallo et al., 1988), and the secretion of neuroendocrine hormones (Iovino et al., 1988; Cunningham et al., 1994). In the current study, we demonstrated intravenous GLP-1R agonists induced Fos-IR in GLP-1R-expressing neurons in the AP. A recent study using ${ }^{125} \mathrm{I}-\mathrm{GLP}-1$ and ${ }^{125} \mathrm{I}-\mathrm{EXN}-4$ demonstrated that GLP-1 receptors are accessible to peripheral GLP-1 in the subfornical organ and the AP (Goke et al., 1995; Orskov et al., 1996). Together with our findings, peripheral GLP-1 likely directly activate neurons in the AP.

We showed previously that both intravenous and intracerebroventricular administrations of EXN-4 induced Fos-IR in catecholamine neurons and provoked a robust and rapid increase in 
TH hnRNA expression in brainstem catecholamine neurons (Yamamoto et al., 2002). Interestingly, the patterns of Fos-IR and $\mathrm{TH}$ hnRNA expression were distinct in the AP after intravenous and intracerebroventricular administration. Specifically, we found that intravenous EXN-4 induced Fos-IR in neurons of the AP much more than intracerebroventricular administration. These findings led us to hypothesize that catecholamine neurons in the AP are responsive to peripheral GLP-1 but not central GLP-1. In the current study, we found that many catecholamine neurons in the AP expressed GLP-1R and were activated by peripheral GLP-1R agonists. Furthermore, our findings suggest that activation of the GLP-1R induces TH gene expression through the TH promoter. Although still incompletely defined, GLP-1R interacts with heterotrimetric $G_{s}$ proteins (Skoglund et al., 1999) to stimulate adenylate cyclase (Leech et al., 1999), and to increase production of cAMP (Drucker et al., 1987). Because the TH promoter contains cAMP-responsive element (Lazaroff et al., 1995), we hypothesize that the stimulatory effect of GLP-1 on TH promoter activity is mediated via a cAMP signaling mechanism. Interestingly, catecholamine neurons in the AP have been suggested to be involved in mediating several autonomic functions, including cardiovascular responses and emesis (Armstrong et al., 1981, 1982; Miceli et al., 1987), which, as noted, peripheral GLP-1 may also induce.

The AP has no direct efferent projections to the hypothalamus and autonomic preganglionic neurons (Shapiro and Miselis, 1985; Cunningham et al., 1994). The targets of the AP projections are relatively restricted and include neurons, including the PBel, the RVLM, and the NTS (van der Kooy and Koda, 1983; Shapiro and Miselis, 1985; Miceli et al., 1987; Herbert et al., 1990; Cunningham et al., 1994). In the current study, we found that many catecholamine AP neurons projecting to the PBel were activated by EXN-4. The PB has been suggested to occupy a key position in the central autonomic network, as in interface between medullary control sites and forebrain nuclei involved in autonomic integration (Saper, 1995). Specifically, neurons in the PBel project topographically to the amygdala. This pathway has been implicated in gustatory, chemosensitive, respiratory, cardiovascular, and nociceptive processes (Herbert et al., 1990; Bernard et al., 1993). Interestingly, intravenous GLP-1 agonists induced Fos-IR in the central nucleus of the amygdala, suggesting that GLP-1-activated neurons in the AP may be involved in several autonomic functions in part by engaging parabrachioamygdaloid projection. The NTS receives major inputs from the AP (Kachidian and Pickel, 1993; Cunningham et al., 1994; Saper, 1995). We found several catecholamine and noncatecholamine neurons in the AP that innervate the caudal NTS (Kachidian and Pickel, 1993). Interestingly, we also found that intravenous EXN-4 activates GLP-1 neurons in the caudal NTS in our preliminary study (Yamamoto et al., 2002). Thus, we hypothesize that GLP-1 neurons in the caudal NTS receive input from catecholamine neurons in the AP. This input activates GLP-1 neurons, which in turn innervate and activate cell groups expressing GLP-1Rs in the brainstem and hypothalamus. We also found catecholamine neurons in the AP that innervate the RVLM, many of which were activated by EXN-4. The RVLM is well known to be a critical control site in regulating cardiovascular responses (Guyenet et al., 1989) and has descending projections to the sympathetic preganglionic neurons (Ross et al., 1984). We suggest that projections from the AP to the RVLM may be a possible peripheral GLP-1-activated pathway to engage autonomic responses, including cardiovascular responses (Yamamoto et al., 2002).

\section{Potential pathophysiological roles of GLP-1}

Peripheral GLP-1 promotes nutrient assimilation via stimulation of glucose-dependent insulin release from pancreatic $\beta$ cells. 
Thus, GLP-1R agonists such as EXN-4 are currently in clinical trials as a treatment for type II diabetes (Drucker, 1998). Recently, we demonstrated that central GLP-1 activates sympathetic outflow, including blood pressure, heart rate, and the induction of Fos-IR in the adrenal medulla (Yamamoto et al., 2002). Our previous and current findings suggest that activation of central autonomic pathways is a potential side effect of GLP-1 drugs used in the treatment of diabetes mellitus. Previous studies have demonstrated that exaggerated plasma concentrations of GLP-1 precede reactive hypoglycemia after oral glucose and contribute to the pathophysiology of the late dumping syndrome (Kreymann et al., 1987; Toft-Nielsen et al., 1998; Gebhard et al., 2001). The dumping syndrome is a constellation of responses that is relatively common in patients who have undergone a gastrectomy (Hasler, 2002). The dumping syndrome also has an early component that is characterized by exaggerated sympathetic responses. Although experimental data are still lacking, it is intriguing to speculate that exaggerated plasma concentrations of GLP-1 may also contribute to the pathophysiology of the early phase of the dumping syndrome. Postprandial serum catecholamine levels are significantly higher in dumping syndrome that is paralleled by a transient increase in serum GLP-1 level (Gebhard et al., 2001). To date, no effects of GLP-1 on postprandial symptoms have been reported in healthy human (Delgado-Aros et al., 2002). However, on the basis of our findings, we hypothesize that activation of catecholaminergic neurons in the AP by GLP-1 and their downstream targets may contribute to the pathophysiology of the early dumping syndrome.

In summary, we report that GLP-1-responsive catecholamine neurons in the AP link peripheral GLP-1 with autonomic control sites. We hypothesize that these projections play a critical role in the regulation of rapid homeostatic responses to metabolic stressors and contribute to the regulation of blood pressure and heart rate, food and water intake, emesis, conditioned taste aversion, and the secretion of neuroendocrine hormones.

\section{References}

Armstrong DM, Pickel VM, Joh TH, Reis DJ, Miller RJ (1981) Immunocytochemical localization of catecholamine synthesizing enzymes and neuropeptides in area postrema and medial nucleus tractus solitarius of rat brain. J Comp Neurol 196:505-517.

Armstrong DM, Pickel VM, Joh TH, Reis DJ (1982) Electron microscopic immunocytochemical localization of tyrosine hydroxylase in the area postrema of rat. J Comp Neurol 206:259-272.

Asfari M, Janjic D, Meda P, Li G, Halban PA, Wollheim CB (1992) Establishment of 2-mercaptoethanol-dependent differentiated insulinsecreting cell lines. Endocrinology 130:167-178.

Barragan JM, Eng J, Rodriguez R, Blazquez E (1999) Neural contribution to the effect of glucagon-like peptide-1-(7-36) amide on arterial blood pressure in rats. Am J Physiol 277:E784-E791.

Bernard JF, Alden M, Besson JM (1993) The organization of the efferent projections from the pontine parabrachial area to the amygdaloid complex: a Phaseolus vulgaris leucoagglutinin (PHA-L) study in the rat. J Comp Neurol 329:201-229.

Carpenter DO (1990) Neural mechanisms of emesis. Can J Physiol Pharmacol 68:230-236.

Chan RK, Sawchenko PE (1994) Spatially and temporally differentiated patterns of c-fos expression in brainstem catecholaminergic cell groups induced by cardiovascular challenges in the rat. J Comp Neurol 348:433-460.

Chan RK, Brown ER, Ericsson A, Kovacs KJ, Sawchenko PE (1993) A comparison of two immediate-early genes, c-fos and NGFI-B, as markers for functional activation in stress-related neuroendocrine circuitry. J Neurosci 13:5126-5138.

Creutzfeldt W (2001) The entero-insular axis in type 2 diabetes-incretins as therapeutic agents. Exp Clin Endocrinol Diabetes 109:S288-S303.

Cunningham Jr ET, Miselis RR, Sawchenko PE (1994) The relationship of efferent projections from the area postrema to vagal motor and brain stem catecholamine-containing cell groups: an axonal transport and immunohistochemical study in the rat. Neuroscience 58:635-648.

Delgado-Aros S, Kim DY, Burton DD, Thomforde GM, Stephens D, Brinkmann BH, Vella A, Camilleri M (2002) Effect of GLP-1 on gastric volume, emptying, maximum volume ingested, and postprandial symptoms in humans. Am J Physiol Gastrointest Liver Physiol 282:G424-G431.

Drucker DJ (1998) Glucagon-like peptides. Diabetes 47:159-169.

Drucker DJ, Philippe J, Mojsov S, Chick WL, Habener JF (1987) Glucagonlike peptide I stimulates insulin gene expression and increases cyclic AMP levels in a rat islet cell line. Proc Natl Acad Sci USA 84:3434-3438.

Edwards GL, Ritter RC (1981) Ablation of the area postrema causes exaggerated consumption of preferred foods in the rat. Brain Res 216:265-276.

Elias CF, Saper CB, Maratos-Flier E, Tritos NA, Lee C, Kelly J, Tatro JB, Hoffman GE, Ollmann MM, Barsh GS, Sakurai T, Yanagisawa M, Elmquist JK (1998) Chemically defined projections linking the mediobasal hypothalamus and the lateral hypothalamic area. J Comp Neurol 402:442-459.

Elmquist JK, Saper CB (1996) Activation of neurons projecting to the paraventricular hypothalamic nucleus by intravenous lipopolysaccharide. J Comp Neurol 374:315-331.

Elmquist JK, Scammell TE, Saper CB (1997) CNS Responses to immune system challenge: mechanisms of the febrile response. Trends Neurosci 20:565-570.

Ferguson AV, Marcus P (1988) Area postrema stimulation induced cardiovascular changes in the rat. Am J Physiol 255:R855-R860.

Ferguson AV, Smith P (1991) Autonomic mechanisms underlying area postrema stimulation-induced cardiovascular responses in rats. Am J Physiol 261:R1-R8.

Gallo M, Arnedo M, Aguero A, Puerto A (1988) Electrical intracerebral stimulation of the area postrema on taste aversion learning. Behav Brain Res 30:289-296.

Gebhard B, Holst JJ, Biegelmayer C, Miholic J (2001) Postprandial GLP-1, norepinephrine, and reactive hypoglycemia in dumping syndrome. Dig Dis Sci 46:1915-1923.

Goke R, Fehmann HC, Linn T, Schmidt H, Krause M, Eng J, Goke B (1993) Exendin-4 is a high potency agonist and truncated exendin-(9-39)-amide an antagonist at the glucagon-like peptide 1-(7-36)-amide receptor of insulin-secreting beta-cells. J Biol Chem 268:19650-19655.

Goke R, Larsen PJ, Mikkelsen JD, Sheikh SP (1995) Distribution of GLP-1 binding sites in the rat brain: evidence that exendin- 4 is a ligand of brain GLP-1 binding sites. Eur J Neurosci 7:2294-2300.

Guyenet PG, Haselton JR, Sun MK (1989) Sympathoexcitatory neurons of the rostroventrolateral medulla and the origin of the sympathetic vasomotor tone. Prog Brain Res 81:105-116.

Harris M, Aschkenasi C, Elias CF, Chandrankunnel A, Nillni EA, Bjoorbaek C, Elmquist JK, Flier JS, Hollenberg AN (2001) Transcriptional regulation of the thyrotropin-releasing hormone gene by leptin and melanocortin signaling. J Clin Invest 107:111-120.

Hasler WL (2002) Dumping syndrome. Curr Treat Options Gastroenterol 5:139-145.

Herbert H, Moga MM, Saper CB (1990) Connections of the parabrachial nucleus with the nucleus of the solitary tract and the medullary reticular formation in the rat. J Comp Neurol 293:540-580.

Iovino M, Papa M, Monteleone P, Steardo L (1988) Neuroanatomical and biochemical evidence for the involvement of the area postrema in the regulation of vasopressin release in rats. Brain Res 447:178-182.

Jin SL, Han VK, Simmons JG, Towle AC, Lauder JM, Lund PK (1988) Distribution of glucagonlike peptide I (GLP-I), glucagon, and glicentin in the rat brain: an immunocytochemical study. J Comp Neurol 271:519-532.

Kachidian P, Pickel VM (1993) Localization of tyrosine hydroxylase in neuronal targets and efferents of the area postrema in the nucleus tractus solitarii of the rat. J Comp Neurol 329:337-353.

Kieffer TJ, Heller RS, Unson CG, Weir GC, Habener JF (1996) Distribution of glucagon receptors on hormone-specific endocrine cells of rat pancreatic islets. Endocrinology 137:5119-5125.

Kim JG, Baggio LL, Bridon DP, Castaigne JP, Robitaille MF, Jette L, Benquet C, Drucker DJ (2003) Development and characterization of a glucagonlike peptide 1-albumin conjugate: the ability to activate the glucagon-like peptide 1 receptor in vivo. Diabetes 52:751-759.

Kreymann B, Williams G, Ghatei MA, Bloom SR (1987) Glucagon-like peptide-1 7-36: a physiological incretin in man. Lancet 2:1300-1304. 
Lazaroff M, Patankar S, Yoon SO, Chikaraishi DM (1995) The cyclic AMP response element directs tyrosine hydroxylase expression in catecholaminergic central and peripheral nervous system cell lines from transgenic mice. J Biol Chem 270:21579-21589.

Leech CA, Castonguay MA, Habener JF (1999) Expression of adenylyl cyclase subtypes in pancreatic beta-cells. Biochem Biophys Res Commun 254:703-706.

Merchenthaler I, Lane M, Shughrue P (1999) Distribution of pre-proglucagon and glucagon-like peptide-1 receptor messenger RNAs in the rat central nervous system. J Comp Neurol 403:261-280.

Miceli MO, Post CA, van der Kooy D (1987) Catecholamine and serotonin colocalization in projection neurons of the area postrema. Brain Res 412:381-385

Orskov C, Poulsen SS, Moller M, Holst JJ (1996) Glucagon-like peptide I receptors in the subfornical organ and the area postrema are accessible to circulating glucagon-like peptide I. Diabetes 45:832-835.

Paxinos G, Watson C (1986) The rat brain in stereotaxic coordinates, Ed 2. New York: Academic.

Priestley JV, Wotherspoon G, Savery D, Averill S, Rattray M (1993) A combined in situ hybridization and immunofluorescence procedure allowing visualisation of peptide mRNA and serotonin in single sections. J Neurosci Methods 48:99-110.

Ritter S, Taylor JS (1990) Vagal sensory neurons are required for lipoprivic but not glucoprivic feeding in rats. Am J Physiol 258:R1395-R1401.

Ross CA, Ruggiero DA, Joh TH, Park DH, Reis DJ (1984) Rostral ventrolateral medulla: selective projections to the thoracic autonomic cell column from the region containing $\mathrm{Cl}$ adrenaline neurons. J Comp Neurol 228:168-185.

Rowland NE, Crews EC, Gentry RM (1997) Comparison of Fos induced in rat brain by GLP-1 and amylin. Regul Pept 71:171-174.

Saper CB (1995) Central autonomic system., Ed 2. San Diego: Academic Press.

Schimmel JJ, Crews L, Roffler-Tarlov S, Chikaraishi DM (1999) $4.5 \mathrm{~kb}$ of the rat tyrosine hydroxylase 5' flanking sequence directs tissue specific expression during development and contains consensus sites for multiple transcription factors. Brain Res Mol Brain Res 74:1-14.

Scrocchi LA, Brown TJ, MaClusky N, Brubaker PL, Auerbach AB, Joyner AL, Drucker DJ (1996) Glucose intolerance but normal satiety in mice with a null mutation in the glucagon-like peptide 1 receptor gene. Nat Med $2: 1254-1258$
Seeley RJ, Blake K, Rushing PA, Benoit S, Eng J, Woods SC, D'Alessio D (2000) The role of CNS glucagon-like peptide-1 (7-36) amide receptors in mediating the visceral illness effects of lithium chloride. J Neurosci 20:1616-1621.

Shapiro RE, Miselis RR (1985) The central neural connections of the area postrema of the rat. J Comp Neurol 234:344-364.

Skoglund G, Basmaciogullari A, Rouot B, Marie JC, Rosselin G (1999) Cellspecific localization of $G$ protein alpha-subunits in the islets of Langerhans. J Endocrinol 162:31-37.

Skoglund G, Hussain MA, Holz GG (2000) Glucagon-like peptide 1 stimulates insulin gene promoter activity by protein kinase A-independent activation of the rat insulin I gene cAMP response element. Diabetes 49:1156-1164.

Toft-Nielsen M, Madsbad S, Holst JJ (1998) Exaggerated secretion of glucagon-like peptide-1 (GLP-1) could cause reactive hypoglycaemia. Diabetologia 41:1180-1186.

Turton MD, O'Shea D, Gunn I, Beak SA, Edwards CM, Meeran K, Choi SJ, Taylor GM, Heath MM, Lambert PD, Wilding JP, Smith DM, Ghatei MA Herbert J, Bloom SR (1996) A role for glucagon-like peptide-1 in the central regulation of feeding. Nature 379:69-72.

van der Kooy D, Koda LY (1983) Organization of the projections of a circumventricular organ: the area postrema in the rat. J Comp Neurol 219:328-338.

Wheeler MB, Lu M, Dillon JS, Leng XH, Chen C, Boyd AE, 3rd (1993) Functional expression of the rat glucagon-like peptide-I receptor, evidence for coupling to both adenylyl cyclase and phospholipase-C. Endocrinology 133:57-62.

Yamamoto H, Lee CE, Marcus JN, Williams TD, Overton JM, Lopez ME, Hollenberg AN, Baggio L, Drucker DJ, Elmquist JK (2002) Central administration of glucagon-like peptide-1 receptor agonist increases blood pressure and heart rate, activates autonomic regulatory neurons. J Clin Invest 110:43-52.

Young AA, Gedulin BR, Bhavsar S, Bodkin N, Jodka C, Hansen B, Denaro $M$ (1999) Glucose-lowering and insulin-sensitizing actions of exendin-4: studies in obese diabetic (ob/ob, db/db) mice, diabetic fatty Zucker rats, and diabetic rhesus monkeys (Macaca mulatta). Diabetes 48:1026-1034.

Zhang YH, Lu J, Elmquist JK, Saper CB (2000) Lipopolysaccharide activates specific populations of hypothalamic and brainstem neurons that project to the spinal cord. J Neurosci 20:6578-6586. 